Research Paper

\title{
Management of salivary gland carcinomas - a review
}

\author{
Xiaoli Wang ${ }^{1,2}$, Yijun Luo ${ }^{1,2}$, Minghuan $\mathrm{Li}^{2}$, Hongjiang $\mathrm{Yan}^{2}$, Mingping Sun ${ }^{2}$ and \\ Tingyong Fan ${ }^{2}$ \\ ${ }^{1}$ School of Medical and Life Sciences, University of Jinan-Shandong Academy of Medical Sciences, Jinan, Shandong, China \\ 2 Department of Radiation Oncology, Shandong Cancer Hospital and Institute, Jinan, Shandong, China \\ Correspondence to: Tingyong Fan, email: fanty681105@163.com \\ Keywords: salivary gland cancers, adenoid cystic carcinoma, elective neck dissection, chemotherapy, targeted therapy \\ Received: June 16, 2016 \\ Accepted: December 08, 2016 \\ Published: December 15, 2016
}

\section{ABSTRACT}

Salivary gland carcinomas are a heterogeneous group of tumors with many histological subtypes which occur in both major and minor salivary glands. However, they have a relatively low of incidence. Their rarity limits study size and the ability to perform phase III trials. Therefore, to date, the entire management is usually varied. Certain published studies have paid more attention to the systemic therapy in the management of metastatic or locally recurrent salivary gland cancer, while little effort has been made to study the entire management for this lesions. Although results of treatment for patients with salivary gland carcinoma have improved in recent years, the treatment of salivary gland cancers is still not standardized. And some patients who haven't received optimal treatment strategies had a reduced survival. In this review, the topics covered include surgery and radiotherapy, selective neck dissection, chemotherapy, and targeted therapy, which aimed to summarize the optimal management approaches and to develop recommendations for managing this lesions. For these rare cancers, there is also a need for a determined, coordinated effort to conduct high-quality clinical trials.

\section{INTRODUCTION}

Salivary gland cancers (SGCs) are relatively rare, accounting for $1-6 \%$ of all neoplasms of the head and neck, and are diverse with respect to origin and pathology. [1] They are classified according to the 2005 World Health Organization, which lists 24 different histologic subtypes.[2] The most common histopathologic types are as follows: mucoepidermoid carcinoma (MEC), adenoid cystic carcinoma (ACC), adenocarcinoma not otherwise specified and salivary duct carcinoma. In general, they are typically divided into those arising from the major salivary glands and those arising from the minor salivary glands. Parotid glands is the most common site of major SGCs, followed by submandibular glands and sublingual glands. Also, minor salivary glands are the source of SGCs, representing for $9-23 \%$ of all salivary gland tumors.[3-5] Oral cavity is the most common site of minor SGCs, and hard palate is the most frequent subsite, as demonstrated in the previous studies.[3, 6-8] In contrast to major salivary gland tumors are almost benign, up to $80 \%$ of tumors arising from the minor salivary glands are malignant.[9, 10] Primary carcinomas originating from major salivary glands can be staged according to the 7th edition of the Union for International Cancer Control (UICC), whereas the stage of minor SGCs is mainly according to the primary site of the lesions.

Complete surgical resection, with adequate free margins, is currently the mainstay treatment for SGCs. Elective treatment of the N0 neck remains a controversial topic. Postoperative radiotherapy (PORT) can be used as an adjuvant therapy in patients with high-risk factors. And little is known about the efficacy of chemotherapy for advanced SGCs due to the rarity of the disease. It's still a great challenge to select effective therapeutic pathways for patients with recurrent tumors and those with unresectable or metastatic cancer.

In addition, very few clinical trials were designed to investigate the efficacy of novel treatment strategies. In the present review, the topics covered include surgery and radiotherapy, selective neck dissection, chemotherapy, and targeted therapy, which aimed to summarize the optimal management approaches and therapeutic outcomes 
Table 1: PORT vs. RT alone

\begin{tabular}{|c|c|c|c|c|c|c|c|c|}
\hline \multirow{2}{*}{ Study } & \multirow{2}{*}{ Year } & \multicolumn{2}{|c|}{ Neck treatment } & \multirow{2}{*}{ Treatment } & \multirow{2}{*}{ Median dosage } & \multirow{2}{*}{$n$} & \multirow{2}{*}{ Survival rate } & \multirow{2}{*}{$\boldsymbol{P}$} \\
\hline & & RT & ND & & & & & \\
\hline Liu et al. [11] & 2008 & 9 & - & $\begin{array}{c}\mathrm{S}+\mathrm{RT} \\
\mathrm{RT} \\
\end{array}$ & $\begin{array}{l}\text { 69.7 Gy } \\
71.4 \mathrm{~Gy}\end{array}$ & $\begin{array}{l}10 \\
10 \\
\end{array}$ & $\begin{array}{c}54.8 \%(5 \text {-year OS }) \\
0 \% \\
\end{array}$ & 0.024 \\
\hline Cianchetti et al. [12] & 2009 & - & 21 & $\begin{array}{l}\mathrm{S}+\mathrm{RT} \\
\mathrm{RT}\end{array}$ & $\begin{array}{l}\text { 69.6 Gy } \\
74.3 \mathrm{~Gy}\end{array}$ & $\begin{array}{l}76 \\
64\end{array}$ & $\begin{array}{c}55 \%(10-\text { year OS }) \\
35 \%\end{array}$ & 0.027 \\
\hline Mendenhall et al. [13] & 2005 & 120 & 59 & $\begin{array}{c}\mathrm{S}+\mathrm{R} \\
\mathrm{RT}\end{array}$ & $\begin{array}{l}\text { 66 Gy } \\
74.0 \mathrm{~Gy}\end{array}$ & $\begin{array}{c}160 \\
64\end{array}$ & $\begin{array}{c}48 \%(10 \text {-year OS }) \\
35 \%\end{array}$ & 0.0482 \\
\hline Mendenhall et al. [14] & 2004 & 55 & 13 & $\begin{array}{l}\mathrm{S}+\mathrm{RT} \\
\mathrm{RT}\end{array}$ & $\begin{array}{l}67.8 \mathrm{~Gy} \\
72.4 \mathrm{~Gy}\end{array}$ & $\begin{array}{l}59 \\
42\end{array}$ & $\begin{array}{c}77 \% \text { (5-year AS) } \\
57 \%\end{array}$ & NS \\
\hline Terhaard et al. [15] & 2005 & 120 & - & $\mathrm{S}+\mathrm{RT}$ & $\begin{array}{l}62.6 \mathrm{~Gy} \\
63 \mathrm{~Gy}\end{array}$ & $\begin{array}{c}386 \\
40\end{array}$ & $\begin{array}{c}94 \% \text { (5-year LC) } \\
50 \%\end{array}$ & $<0.0005$ \\
\hline Schramn et al. [16] & 2001 & - & 15 & $\mathrm{~S}+\mathrm{RT}$ & $52-66 \mathrm{~Gy}$ & 23 & $67 \%$ (5-year DFS) & NS \\
\hline Iseli et al. [17] & 2009 & - & - & $\begin{array}{l}\mathrm{S}+\mathrm{RT} \\
\mathrm{RT}\end{array}$ & $\begin{array}{l}62.0 \mathrm{~Gy} \\
66.0 \mathrm{~Gy}\end{array}$ & $\begin{array}{l}93 \\
10\end{array}$ & $\begin{array}{c}75.5 \%(10 \text {-year LRFS }) \\
24.6 \%\end{array}$ & 0.001 \\
\hline
\end{tabular}

Abbreviation: $n$, the number of patients; RT, radiotherapy; S, surgery; OS, overall survival; DFS, disease-free survival; AS, absolute survival; LC, local control; LRFS: local recurrence-free survival; NS, not stated.

of these disease and develop recommendations for management of malignancies in salivary gland.

\section{SYSTEMATIC LITERATURE REVIEW}

We performed a systematic literature search via PubMed including articles in the English language. Medical subject headings and main keywords used in the PubMed were salivary gland, malignancy/ carcinoma/cancer, management, elective neck dissection, chemotherapy, and radiotherapy. Relevant articles, abstracts, and review articles were selected and reviewed, we also scanned the references in the retrieved articles.

\section{SURGERY AND RADIOTHERAPY}

In the past, various therapeutic means included surgery, radiotherapy (RT) and chemotherapy were used for SGCs, which mainly depended on the lesions' specific situation, surgeons' clinical judgment, and patients' willingness to undergo resection. Up to now, controversy also exists as to whether RT alone, surgical treatment alone or combined surgery with RT is the optimal therapeutic approach. We have to rely on some studies to discuss about these relevant issues are as follows.

\section{Surgery combined with PORT versus RT alone}

Most patients with early-stage lesions that are resectable generally tend to undergo surgery as their initial therapeutic approach, whereas those with advanced or unresectable cancers tend to be treated with RT alone or chemoradiotherapy (CRT), which hampered the comparison of the efficacy of RT alone with that of surgery combined with adjuvant RT. But some effort had been made to reflect the role of surgery in SGCs. For this part, PORT vs. RT alone studies are summarized in Table 1 .

A retrospective study by Liu et al. revealed that the 5 -year disease free survival (DFS) rate and overall survival (OS) in the surgical treatment group and the nonsurgical treatment group were $68.6 \%$ and $87.5 \%$ vs. $0 \%$ and $47.9 \%$, respectively. Multivariate analysis indicated that surgical treatment was the only independent factor affecting DFS $(P=.015)$, whereas surgical treatment $(P=.024)$ was an independent factors affecting OS. [11] Cianchetti et al. carried out a retrospective analysis and included a series of 140 patients with minor SGCs to analyze the outcomes of patients receiving RT alone or combined RT with surgery. The median RT dose for patients receiving radical RT or PORT patients were 74.3 Gy (range, 50.0-79.2 Gy) and 69.6 Gy (range, 10.5-85 Gy), respectively. They found that patients receiving surgery plus RT had a higher 10year local control (LC) rate ( $86 \%$ vs. $46 \%$, respectively; $P<0.0001)$, 10-year local-regional control rate (76\% vs. $44 \%$, respectively; $P=0.0004), 10$-year cause-specific survival rate $(67 \%$ vs. $44 \%$, respectively; $P=0.0295)$, 10 -year OS rate (55\% vs. $35 \%$, respectively; $P=0.0277)$ than those receiving RT alone. Multivariate analysis also confirmed that treatment modality was a significant factor influencing patients' survival $(P=.0174)$. [12] Similar to the findings mentioned above, Mendenhall et al. [13] studied the treatment outcomes of 101 patients with head and neck ACC, and they found that the 5- and 10-year LC rates of the RT group and the surgery plus RT group were $56 \%$ and $43 \%$ vs. $94 \%$ and $91 \%$, respectively; multivariate analysis of LC revealed that treatment group significantly influenced this endpoint $(P=.0008)$. Moreover, the 5- and 10-year absolute survival rates of RT alone compared with surgery plus RT were $57 \%$ and $42 \%$ vs. $77 \%$ and $55 \%$, respectively, which were consistent 
Table 2: PORT vs. surgery alone

\begin{tabular}{|c|c|c|c|c|c|c|c|c|}
\hline Study & Year & Treatment & Median dosage & $N$ & Survival rate & $\boldsymbol{P}$ & $\mathrm{LC} / \mathrm{RC}$ rate & $p$ \\
\hline Armstrong et al. [22]* & 1990 & $\begin{array}{l}\text { PORT } \\
\text { S }\end{array}$ & 56.6 Gy & $\begin{array}{l}46 \\
46\end{array}$ & $\begin{array}{l}51 \%(5 \text {-year DS }) \\
10 \%\end{array}$ & 0.015 & $\begin{array}{l}51.3 \%(5 \text {-year LC) } \\
16.8 \%\end{array}$ & 0.14 \\
\hline Terhaard et al. [15] & 2005 & $\begin{array}{l}\text { PORT } \\
\mathrm{S} \\
\end{array}$ & $62.6 \mathrm{~Gy}$ & \begin{tabular}{|l|}
386 \\
112 \\
\end{tabular} & NS & & $\begin{array}{l}91 \%(10 \text {-year LC) } \\
76 \%\end{array}$ & 0.0005 \\
\hline Storey et al. [23] & 2001 & \begin{tabular}{|l|} 
PORT \\
S
\end{tabular} & $60.0 \mathrm{~Gy}$ & $\begin{array}{l}83 \\
83 \\
\end{array}$ & NS & & $\begin{array}{l}88 \% \text { (5-year LRC) } \\
50 \%\end{array}$ & $<0.05$ \\
\hline North et al. [24] & 1990 & $\begin{array}{l}\text { PORT } \\
\text { S } \\
\end{array}$ & $60.0 \mathrm{~Gy}$ & \begin{tabular}{|l|}
50 \\
19 \\
\end{tabular} & $\begin{array}{l}75 \%(5 \text {-year AS }) \\
59 \%\end{array}$ & 0.014 & NS (10-year LC) & $<0.001$ \\
\hline Le et al. [26] & 1999 & PORT & $60.0 \mathrm{~Gy}$ & 52 & $63 \%(10$-year OS) & $\mathrm{NS}$ & $88 \%$ (10-year LC) & NS \\
\hline Terhaard et al. [27]\# & 2003 & $\begin{array}{l}\text { PORT } \\
\mathrm{S} \\
\end{array}$ & $62.0 \mathrm{~Gy}$ & $\begin{array}{l}385 \\
113 \\
\end{array}$ & NS & NS & $\begin{array}{l}89 \%(10 \text {-year RC) } \\
67 \%\end{array}$ & 0.03 \\
\hline
\end{tabular}

Abbreviation: $\mathrm{n}$, the number of patients; S, surgery; PORT, postoperative radiotherapy; LC, local control; RC, regional control; LRC, locoregional control; DS, determinate survival; AS, actuarial survival; NS: not stated; OS, overall survival; *, for patients with III and IV disease; \#, for $\mathrm{N}+$ patient

with the results of another study of Mendenhall et al. [14] Terhaard et al reported on 426 patients with minor salivary gland carcinomas treated with primary or postoperative radiotherapy in centers of the Dutch Head and Neck Oncology Cooperative Group. 386 patients were in PORT group with a median dose of 62 Gy. Primary radiotherapy $(n=40)$ was given for unresectable disease or M1, with a dose range of 28-74 Gy. The 5-year local control were $94 \%$ for PORT vs. $50 \%$ for primary radiotherapy. [15] Schramm and Imola study revealed that patients with locally advanced stage can also benefit from surgical treatment. They enrolled 23 patients presenting with T3T4 lesion in the nasopharynx who received combined surgical resection with RT. The treatment outcomes were as follows: the 5- and 10-year DFS rates were 67\% and $48 \%$, respectively, and the 5-year local control rate was $77 \%$. [16] Therefore, good survival outcomes might be achieved by combined extensive surgical treatment with RT for patients presenting with T3-T4 lesions.

Besides, the value of salvage surgery remains significant. Iseli et al. found that the 5-year survival rate was significantly better for locally recurrent patients who received salvage surgical treatment than who didn't $(P$ $=.006)$. The median survival time were 90.0 and 14.7 months, respectively. [17] Other studies also indicated that surgical treatment significantly influenced OS for patients presenting with recurrent disease $(P<.0001)$. [18-20] In addition, primary RT is mainly reserved for patients with inoperable disease, those who refuse surgery or those who have an unresectable lesion.

\section{Surgery combined PORT versus surgery alone}

Takes its unique clinical behavior into consideration, surgery does represent a potential treatment option, especially for ACC. Besides, it's also considered to be high-grade malignancy and often treated with combinedmodality therapy. Available data comparing surgery alone with surgery plus PORT that used to verify the role of adjuvant RT had reflected in some retrospective studies. For this part, PORT vs. surgery alone studies are summarized in Table 2.

Terhaard et al. in a large retrospective study enrolled 498 patients presenting with malignant SGCs who received surgery follow by RT $(n=398)$ or surgery alone $(n=112)$. Despite a greater frequency of poor prognostic features in the radiation therapy group, such as more positive neck nodes, more locally-advanced tumors, they also revealed that the relative risk of local recurrence in patients receiving surgery alone was 9.7-fold that of patients receiving combined surgery with RT. And the 5- and 10- years of actuarial local control rates were significantly higher for combined surgery with RT (94\% vs. $84 \%$ for surgery alone, $91 \% v s .76 \%$ for surgery alone) $(P=0.0005)$. In addition, PORT significantly improved 10 -year local control rate compared with surgery alone in patients with high-risk factors for SGCs, such as T3-4 tumors $(84 \%$ vs. $18 \%, p<0.001)$, close resection margins (95\% vs. 55\%, $P=0.003)$, incomplete resection (82\% vs. $44 \%, p<0.001)$, bone invasion confirmed by pathologic $(86 \%$ vs. 54\%, $P=0.04)$, and perineural invasion $(88 \%$ vs. $60 \%, P=0.01)$. Also, PORT significantly improved regional control compare with surgery alone in the $\mathrm{pN}+$ neck $(86 \%$ vs. $62 \%, P=0.03)$.[15]. Zeidan et al. used the SEER database to investigate the role of adjuvant RT in minor SGCs. Multivariate Cox analysis showed adjuvant RT correlated with a $24 \%$ survival advantage as compared to surgery alone (HR $0.76, p=0.02$ ). And advanced T/N category, adenoid cystic histology, high grade, and nasal cavity/paranasal sinus location were also associated with decreased survival. [21]

A matched-pair analysis conducted by Armstrong et al. included 46 patients with previously untreated, non-metastatic malignancies of major salivary gland origin who received combined surgery and RT between 1966 and 1982, compared with 46 patients treated with 
surgery only between 1939 and 1965, who were matched according to prognostic criteria. They found that the 5-year determinate survival and 5-year local control for stage III (Tl-2, N1, M0) or IV (T3-4, N1, M0 or T4, N0, M0) disease in patients who received combined-modality therapy versus patients who underwent surgery alone were $51 \%$ vs. $10 \%(P=.015)$ and $51 \%$ vs. $17 \%(P=.014)$, while no significance was found in 5-year determinate survival for all patients and stage I and II patients. For patients with nodal metastases, the 5-year determinate survival for PORT and surgery alone was $49 \%$ vs. $19 \%$ $(P=.015)$. The corresponding 5-year local-regional control rate was $69 \%$ vs. $40 \%(P=.05)$.[22] There are some other studies have showed that PORT for head and neck SGCs improves locoregional control and long-term survival in patients with locally advanced disease, highgrade (poor-differentiated) tumors, positive margins, perineural invasion, or positive lymph nodes.[23, 24] Storey et al. revealed that adenocarcinoma, high-grade histology were associated with decreased locoregional control and DFS, and high-risk patients presented with submandibular gland lesions received combined surgery and PORT had a better 10-year actuarial locoregional control rate $(88 \%$ in the current study vs. $50 \%$ for surgery alone in previous studies). [23] Le et al. also indicated that patients with adenocarcinoma histology, and sinonasal and oropharyngeal primary sites were associated with worse local control. [26]

However, for the early stage (I and II) disease, some authors demonstrated that the addition of PORT didn't bring survival benefit. A study conducted by Terhaard et al. revealed that the addition of PORT hasn't improved the 10-year local control, compared with patients received surgery alone in T1 (95\% vs. 83\%, $P=$ not significant) or T2 (91\% vs. 88\%, $P=$ not significant) lesion. Furthermore, for patients with negative resection margin, 10-years local control rate was $98 \%$ for patients with PORT vs. $90 \%$ with surgery alone ( $P=$ not significant).[15] Armstrong et al. also found that no significantly better combined with PORT in 5-year determinate survival for stage I and II patients (81.9\% vs.95.8\% for surgery alone; $P=$ not significant).[22] Therefore, some scholars considered that PORT can be omitted without loss of disease control only when early-stage (stages I and II) patients with clear margin, and without adverse prognostic factors such as lymphovascular or perineural invasion that is a set of conditions usually restricted to low-grade variants.[25-28]

In summary, surgery predominates the treatment for SGCs, and PORT was recommended in patients with adverse prognostic factors, such as T3 or T4 tumors, close or incomplete resection margins, high grade, perineural or vascular invasion, and positive lymph nodes. While, the role of adjuvant RT for T1 or T2 patients with complete resection hasn't been confirmed. Primary radiation therapy, particularly, fast neutron radiotherapy appears to be the treatment of choice for patients with inoperable tumors or those with other comorbidities. Thus, for the most part, patients treated with primary radiotherapy had an unfavorabe prognosis. Due to the lack of randomized prospective trials, the benefit of adjuvant RT has never been demonstrated.[29, 30] Therefore, Large-scale, prospective clinical trials should be conducted to verify the value of adjuvant RT.

\section{ELECTIVE NECK DISSECTION}

Cervical lymph node status is an important prognostic predictor for SGCs. [18-20]Recent and past studies are consistent in revealing a reduced survival in patients with positive lymph node at time of primary therapy, and the 5-year survival rate was significant different with or without cervical lymph node metastasis (44-48 \% vs. 73-77\%). [20, 31-34]Therefore, management of the cervical lymph nodes warrants particular discussion. For patients with clinically positive cervical lymph node, therapeutic neck dissection (TND) is still strongly recommended at the time of primary surgery followed by adjuvant RT, regardless of histology or site. $[35,36]$ However, elective treatment of the clinical N0 neck remains a controversial topic. And treatment of the clinically negative neck included observation, elective ND, and prophylactic radiation.

The incidence of occult lymph node metastasis from SGC has generally been reported to range from $10 \%$ to $20 \%$. [37, 38] Elective neck dissection (END) should be indicated when the risk of subclinical disease in a clinically negative neck exceeds 15\%.[36] Hence, it would be of great value to formulate a criteria to select patients for whom a neck dissection should be incorporated into the surgical management of the primary tumor.

Intuitively, the histology type of the primary tumor should be an important factor in the risk of occult metastasis. Over the past decades, several studies have shown that certain tumor pathologies carry a powerful significant trend in the risk of occult nodal involvement. A large retrospective study conducted by Lloyd et al. enrolled a total of 2667 patients of minor SGCs and found that $426(16.0 \%)$ of cases had neck nodal involvement. They revealed that histologic grade was a significant predictor of nodal metastasis for MEC or adenocarcinoma but not for ACC.[39] As is known to all, certain histological type, such as ACC, is associated with a low rate of lymph node metastasis. [23, 40] Spiro et al. ever reported the lymph node metastasis rate about ACC in the major and minor salivary glands was $7.4 \%$ on initial presentation. [31] Jenkins et al. and Spiro et al. revealed that elective surgical treatment was recommended for patients with high-grade cancers such as high-grade MEC or high-grade adenocarcinoma.[41, 42]

In general, high-grade tumors are more frequently associated with occult metastasis than are low-grade tumors. A landmark study was published by Armstrong 
et al. in which the lymph node metastasis rates were retrospectively assessed in 474 SGCs. 47 of 407 patients (12\%) had occult nodal metastasis (i.e. clinically negative, while pathologically positive lymphadenopathy). Multivariate analysis revealed that tumor grade has a statistical significance with occult metastases.[43] And the authors were recommended that END should be only applied for high grade tumors (regardless of histologic type). A recent study also indicated that primary tumor histologic type and tumor grade were statistically significant predictors of occult lymph node disease. The cervical metastases rates of low-, intermediate-, and highgrade tumors were $0 \%, 10 \%$, and $35 \%$, respectively. [44] Schramm and Imola also found a $47 \%$ rate of occult metastasis in clinically node-negative necks (Eight of 14 had poorly-differentiated tumors). [16] Due to relatively high rate of occult neck involvement, Liu et al. also indicated that elective neck treatment included neck resection and radiotherapy was also recommended for patients with cervical negative lymph node, especially for high grade tumors. [45]

More notably, advanced tumor ( $\mathrm{T}$ ) stage is regarded as another important risk factor for occult disease. Armstrong et al. [43] found that among patients with N0 necks, T4lesions had a $24 \%$ risk of occult neck involvement and $16 \%$ for T3 lesions, versus $7 \%$ for $\mathrm{T} 1 / \mathrm{T} 2$ lesions. They also showed an independent increased risk for primary tumors larger than $4 \mathrm{~cm}(20 \%)$ compared with those smaller than $4 \mathrm{~cm}(4 \%)(P<0.0001)$.Neck treatment was only recommended for high-grade and larger tumors. Lloyd et al. had also revealed advanced (T3-T4) stage was significantly related to lymph node involvement. [39]

Most recently, some scholars proposed that site of primary tumor was a prognostic index of lymph node involvement for SGCs.[15, 39, 46] Site of the primary tumor (oral cavity $9 \%$, parotid gland $25 \%$, submandibular gland $42 \%$, other locations $36 \%$; $p<$ 0.0001 ) was independent prognostic factors for the presence of positive nodes, as shown by Terhaard et al [15]. The authors recommended that elective treatment of the neck nodes is indicated for almost all submandibular tumors, except for $\mathrm{T} 1$ acinic or $\mathrm{T} 1$ adenoid cystic tumors. Elective treatment of the neck for tumors of the oral cavity is seldom indicated. Lloyd et al [39] found that pharyngeal site of primary involvement as predictive of lymph node metastasis for minor SGCs. In some sites such as the sinuses and nasal cavity, tumors can attain large sizes before they present clinically. Liu et al. [46] revealed that primary tumor sites which were located in the submandibular gland (40\%), followed by the buccal mucosa $(38.9 \%)$ were associated with the incidences of cervical metastases. Also, tumor size (>4 $\mathrm{cm}$ ) was recognized as a poor prognostic factor for occult disease $[39,43]$. Parotid tumors with facial paralysis are associated with a high percentage of occult lymph node metastases. [47, 48]
To conclude, a number of evidence suggests that TND should be recommended to those who has clinical or radiologic evidence of cervical node metastasis. While, therapeutic ND could be bring benefit to patients with advanced $\mathrm{T}$ stage, large tumors, or high-grade tumors in clinical N0 neck, especially for MEC and adenocarcinoma. In addition, in terms of the location of tumors, all other locations except the oral cavity should take TND into account.

\section{CHEMOTHERAPY}

As mentioned above, surgery and/or radiotherapy are reserved to treat localized disease, while systemic therapy is of necessity to manage recurrent and/or metastatic SGCs. SGCs are characterized by rather frequent local recurrence and distant metastasis, and no satisfactory method of therapy has been reported. Very few clinical trials were designed to investigate the efficacy of systemic therapy, because of the rarity of the disease. Chemotherapy, which plays an important role in systemic therapy, is generally reserved for the palliative treatment of symptomatic locally recurrent and/or metastatic disease that is not amenable to further surgery or radiation. However, there are no National Comprehensive Cancer Network (NCCN) recommendations concerning specific chemotherapy regimens. Therefore, the treatment of recurrent and/or metastatic patients becomes a challenge. Conventional chemotherapy regimens, such as cisplatin and 5-FU or CAP (cisplatin, doxorubicin, and cyclophosphamide) are still utilized as first-line therapy for patients with advanced lesions. With various agents to be tested, only a few were considered to be effective, such as 5-fluorouracil, doxorubicin, and Cisplatin.[49-53]

Previous studies revealed that the value of chemotherapy has been proven to be limited to deal with the patients with recurrent or metastatic disease and no chemotherapy regimen has been the effort to prolong or improve OS or DFS in these tumors. In a retrospective study, various treatment agents included the chemotherapy or targeted drugs, such as adriamycin, cisplatin, carboplatin, 5-fluorouracil, methotrexate, docetaxel, bacilli Calmette Guerin, were offered to manage the majority of patients with symptomatic metastatic disease. However, the survival rates of patients with distant metastasis were similar with or without chemotherapy (35.2\% vs. $27.6 \%$, $P=0.747)$.[25] A review of systemic therapy in the management of recurrent or metastatic SGCs by Lagha et al. showed that the most effective chemotherapeutic agents seem to be platinum, 5-Fluorouracil and anthracyclines, and recommended that symptomatic locally recurrent or metastatic patients adapt platinum combined with doxorubicin to maximize the likelihood of a response, and for cases of slow disease progression and asymptomatic patients, a single agent therapy is sufficient.[54] However, another review revealed that for the cases of slow disease 
progression and asymptomatic patients, which often occurs in ACC, chemotherapy could be delayed until an evident progression of the disease or to the emergence of symptoms.[55] For single-agent therapy, either cisplatin or paclitaxel isn't recommended for recurrent and/ or metastatic SGCs, on account of lack of availability of less toxic choices (cisplatin) and proven activity (paclitaxel). Whereas a cisplatin-based polychemotherapy for candidate patients may achieve a higher response rate (RR), compared with monochemotherapy (25 vs. 13\%). [56] A meta-analysis, which enrolled about 200 patients with SGCs entered mainly into small Phase II trials, was made to reflect the role of chemotherapy and identified that platinum-based chemotherapy as an independent predictor of increased survival. Chemotherapy in most of these studies elected to the meta-analysis was done as a palliative intent, but the median survival has a significant increased with both platinum-based (2.5 months) and anthracic line-based (4.9 months) chemotherapy.[57]

Therefore, whether chemotherapy combined with PORT can improve OS and DFS or not? On this issue, some scholars had also made some effort to prove the efficiency of postoperative chemoradiotherapy (POCRT). Cisplatin-based therapy was the most common drugs given in combination chemoradiorherapy (CRT). Tanvetyanonet al. performed a case match comparison of POCRT versus PORT, with 12 cases in eachstudy cohort. 11 patients received a platinum-based regimen (8 cisplatin and 3 carboplatin), and only one patient received combined cisplatin and fluorouracil chemotherapy. Although grade 3 or higher toxicity (hematologic) was only seen in patients in the CRT cohort $(n=8)$, in no case was the toxicity severe enough to cause treatment cessation. The outcome revealed that the 3 -year survival rate was $83 \%$ in the CRT group compare with $44 \%$ in the radiationalone group $(P=.05)$. [58] Recent studies have also indicated that POCRT, particularly with platinum-based chemotherapy, showed a trend toward higher locoregional control rates than those treated with PORT alone. [5962] However, because of increased toxicity and mortality with the application of POCRT, some investigators did not recommend the use of POCRT for patients with SGCs. Tanvetyanon et al. conducted another retrospective study to compare adjuvant a platinum-based CRT with adjuvant radiotherapy among the older patient population. They found that treatment with adjuvant CRT was associated with an increased mortality and toxicity when compared to adjuvant radiotherapy.[63] Similarly to Tanvetyanon and the colleagues, Amini et al [64] retrospectively reviewed 2210 patients with resected major salivary gland carcinoma on the basis of the date from the National Cancer Data Base. They found that OS was significantly inferior with adjuvant CRT $(n=368)$ compared with RT alone $(n=1842)(p=.02)$, and patients with multiagent chemotherapy, CRT vs. RT alone appeared to have worse OS, compared with single-agent chemotherapy $(P=.03)$.
Therefore, the Radiation Therapy Oncology Group (RTOG 1008) conducted a phase II randomized trial to explore the utility of a platinum-based adjuvant CRT in highrisk patients. Univariate analysis revealed that the CRT group was identified to have inferior 3-year PFS (42.1\% vs. $73.8 \% ; p<.001)$, 3-year OS $(52.2 \% v s .78 .1 \% ; p=$ $.004)$, locoregional control $(79.3 \%$ vs $91.2 \% ; p=.031)$, and distant metastasis-free survival(52.7\% vs. $83.3 \% ; p<$ $.001)$ rates. Multivariate analysis revealed that there was a trend toward a benefit to PFS from CRT, but it was not statistically significant $(p=.482)$. RTOG 1008 came to a conclusion that the standard use of CRT for high-risk salivary malignancies cannot be recommended. [65]

In summary, chemotherapy as a palliative treatment was applied to patients experiencing with symptomatic locally recurrent and/or metastatic disease which were not amenable to further surgery or radiation. A platinum-based chemotherapy regimen could be bring benefit to patients with incurable SGCs, especially for symptomatic or rapidly progressive patients. Future studies are required to identify new chemotherapeutic agents in order to improve the prognosis in patients with SGCs.

\section{TARGETED THERAPY}

Due to the poor results with chemotherapy, it's urgent to explore novel therapeutic interventions for this disease. And great expectations have been put into individualized therapies: in particular, the EGF receptors family (EGFR and HER2), KIT and androgen receptors are the most commonly investigated molecular targets in SGCs. Their expression seems not to be linked to its pathogenetic role in the development of SGCs, but more to the histogenetic origin of the tumor cells. Various targeted agents, such as imatinib, cetuximab, gefitinib, trastuzumab, had been used for exploring new treatment for SGCs, but on account of the rare incidence of SGCs, the number of cases available on targeted therapy for analysis is relatively small. The following we described was about the targeted therapy of SGCs.

According to the literature reported, high expression of c-kit has been noted in up to $90 \%$ of salivary ACC. [66-70]To this day, the relationship between gene mutation and the mechanism of c-kit activation hasn't been clearly identified in this tumor.[66-70] Owing to the rare incidence of salivary ACC, a total of eight studies have evaluated imatinib in over 80 patients with advanced ACC (7 studies have used imatinib alone, and one study has evaluated imatinib combination with cisplatin), only 4 partial response, with an objective response rate of 5\% and a short response duration (range, 9-15 months).[71-78]

Likewise, it is well established that epidermal growth factor receptor (EGFR) is frequently positive in salivary ACC (74-91\%). So, the EGFR antibody, such as cetuximab, seemed promising. Some effort had been made to evaluate the value of cetuximab. A phase II trial 
conducted by Hitre et al. revealed that the combination of cetuximab with cisplatin for patients with metastatic ACC presented an objective response rate $>40 \%$ and median PFS and OS were 13 and 24 months, respectively. [77] With respect to the outcome, which has improved treatment efficacy compare with those without cetuximab, and side effects were also manageable and endurable. [79] Other EGFR antibody, such as gefitinib, lapatinib, were also used in the treatment of metastatic salivary gland cancer, particularly in ACC. However, therapeutic outcomes were disappointing and failed to achieve any objective responses.[80, 81] Therefore, the antitumor activity of EGFR antibody in metastatic and/or recurrent SGCs still needs to explore further.

Bortezomib, a proteosome inhibitor, which was the first one and the only one to approved to enter clinical. It was also investigated in patients with metastatic ACC to assess its effectiveness. Argiris et al. conducted a phase II trial which enrolled 25 patients with advanced ACC to evaluate the activity of bortezomib. Side effect was well tolerated and did not hamper the treatment course, but no complete or partial responses was found from bortezomib in monotherapy, 15 of 21 evaluable patients (71\%) presenting with best response was stable disease for a median duration of 4.2 months (range: 0-20.1 months). [82]

Up to date, none of the targeted therapies aforementioned have shown any real antitumor activity in SGCs. The best response obtained was PR in a small group of patients, and only a short period of time (a few months). Currently, several trials on targeted therapy involving SGCs are still ongoing.

In addition, other therapy such as hormone therapy has been reported in the literature. Several studies showed that some SGCs possess hormonal receptors, such as estrogen or progesterone or even androgen receptors in salivary duct carcinoma.[83-87]

So far, no phase II studies have been carried out, and the effectiveness of hormone therapy is still a mystery. Therefore, it is very difficult to define the role of hormone therapy in SGCs.

\section{CONCLUSION}

Salivary gland malignancies as a heterogeneous group have a relatively low of incidence, but a variety of histological types. And their rarity limits study size and the ability to perform phase III trials. The current therapies available for the management of patients with SGCs is complete surgical resection, which is the mainstay treatment for these lesions. At the same time, therapeutic ND should be recommended to those who has clinical or radiologic evidence of cervical node metastasis. While, therapeutic ND could be bring benefit to patients with advanced $\mathrm{T}$ stage or high-grade tumors in clinical N0 neck, especially for MEC and adenocarcinoma. For patients with inoperable disease, those who refuse surgery or those who have an unresectable tumor, primary RT should be considered. And PORT was recommended in patients presenting with adverse prognostic factors, such as T3-4 tumors, close or incomplete resection margins, high grade, perineural or vascular invasion, and positive lymph nodes. While, the role of adjuvant RT for T1 or T2 patients with complete resection, and the value of targeted therapies for advanced and/or metastatic patients have never been confirmed. Chemotherapy as palliative treatment to deal with the patients with recurrent and/ or metastatic disease, which has been proven to be of limited effect, and no chemotherapy regimen has been the effort to prolong or improve OS or DFS in these tumors. Meanwhile, the results of targeted therapy have been disappointing, especially the objective responses reported in several studies. Large-scale, prospective clinical trials or phase II trials should be conducted to prove the role of adjuvant treatment, such as chemotherapy, targeted therapy, hormone therapy.

Overall, a broad spectrum of choices exists for the management of SGCs, with surgical treatment at the center for most therapeutic plans. At present, further clinical trials based on collaborative multicentric efforts should be conducted to establish new treatment guidelines for these patients.

\section{CONFLICTS OF INTEREST}

The authors have no conflicts of interest.

\section{REFERENCES}

1. Laurie SA, and Licitra L. Systemic therapy in the palliative management of advanced salivary gland cancers. J Clin Oncol. 2006; 24: 2673-8.

2. Thompson L. World Health Organization classification of tumours: pathology and genetics of head and neck tumours. Ear Nose Throat J. 2006; 85: 74.

3. Spiro RH, Koss LG, Hajdu SI, and Strong EW. Tumors of minor salivary origin. A clinicopathologic study of 492 cases. Cancer. 1973; 31: 117-29.

4. Eveson JW, and Cawson RA. Tumours of the minor (oropharyngeal) salivary glands: a demographic study of 336 cases. J Oral Pathol. 1985; 14: 500-9.

5. Ito FA, Ito K, Vargas PA, de Almeida OP, and Lopes MA. Salivary gland tumors in a Brazilian population: a retrospective study of 496 cases. Int J Oral Maxillofac Surg. 2005; 34: 533-6.

6. Copelli C, Bianchi B, Ferrari S, Ferri A, and Sesenna E. Malignant tumors of intraoral minor salivary glands. Oral Oncol. 2008; 44: 658-63.

7. Pires FR, Pringle GA, de Almeida OP, and Chen SY. Intraoral minor salivary gland tumors: a clinicopathological study of 546 cases. Oral Oncol. 2007; 43: 463-70. 
8. Vander PVL, Balm AJ, Hilgers FJ, Tan IB, Keus RB, and Hart AA. Stage as major long term outcome predictor in minor salivary gland carcinoma. Cancer. 2000; 89: 1195204.

9. Spiro RH. Management of malignant tumors of the salivary glands. Oncology (Williston Park). 1998; 12: 671-80; discussion 683.

10. Iyer NG, Kim L, Nixon IJ, Palmer F, Kraus D, Shaha AR, Shah JP, Patel SG, and Ganly I. Factors predicting outcome in malignant minor salivary gland tumors of the oropharynx. Arch Otolaryngol Head Neck Surg. 2010; 136: 1240-7.

11. Liu TR, Yang AK, Guo X, Li QL, Song M, He JH, Wang YH, Guo ZM, Zhang Q, Chen WQ, and Chen FJ. Adenoid cystic carcinoma of the nasopharynx: 27-year experience. Laryngoscope. 2008; 118: 1981-8.

12. Cianchetti M, Sandow PS, Scarborough LD, Morris CG, Kirwan J, Werning JW, and Mendenhall WM. Radiation Therapy for Minor Salivary Gland Carcinoma. The Laryngoscope 2009; 119(7): 1334-8.

13. Mendenhall WM, Morris CG, Amdur RJ, Werning JW, and Villaret DB. Radiotherapy alone or combined with surgery for salivary gland carcinoma. Cancer. 2005; 103: 2544-50.

14. Mendenhall WM, Morris CG, Amdur RJ, Werning JW, Hinerman RW, and Villaret DB. Radiotherapy alone or combined with surgery for adenoid cystic carcinoma of the head and neck. Head Neck. 2004; 26: 154-62.

15. Terhaard CH, Lubsen H, Rasch CR, Levendag PC, Kaanders HH, Tjho-Heslinga RE, van Den Ende PL, and Burlage $\mathrm{F}$. The role of radiotherapy in the treatment of malignant salivary gland tumors. Int J Radiat Oncol Biol Phys. 2005; 61: 103-11.

16. Schramm VL Jr, and Imola MJ. Management of nasopharyngeal salivary gland malignancy. Laryngoscope. 2001; 111: 1533-44.

17. Iseli TA, Karnell LH, Graham SM, Funk GF, Buatti JM, Gupta AK, Robinson RA, and Hoffman HT. Role of radiotherapy in adenoid cystic carcinoma of the head and neck. J Laryngol Otol. 2009; 123: 1137-44.

18. Mucke T, Robitzky LK, Kesting MR, Wagenpfeil S, Holhweg-Majert B, Wolff KD, and Holzle F. Advanced malignant minor salivary glands tumors of the oral cavity. Oral Surg Oral Med Oral Pathol Oral Radiol Endod. 2009; 108: 81-9.

19. Feinstein TM, Lai SY, Lenzner D, Gooding W, Ferris RL, Grandis JR, Myers EN, Johnson JT, Heron DE, and Argiris A. Prognostic factors in patients with high-risk locally advanced salivary gland cancers treated with surgery and postoperative radiotherapy. Head Neck. 2011; 33: 318-23.

20. Kakarala K, and Bhattacharyya N. Survival in oral cavity minor salivary gland carcinoma. Otolaryngol Head Neck Surg. 2010; 143: 122-6.

21. Zeidan YH, Pekelis L, An Y, Holsinger FC, Kong CS, Chang DT, Le QT. Survival benefit for adjuvant radiation therapy in minor salivary gland cancers. Oral Oncology, 2015; 51: 438-445.

22. Armstrong JG, Harrison LB, Spiro RH, Fass DE, Strong EW, and Fuks ZY. Malignant tumors of major salivary gland origin. A matched-pair analysis of the role of combined surgery and postoperative radiotherapy. Arch Otolaryngol Head Neck Surg. 1990; 116: 290-3.

23. Storey MR, Garden AS, Morrison WH, Eicher SA, Schechter NR, and Ang KK. Postoperative radiotherapy for malignant tumors of the submandibular gland. Int J Radiat Oncol Biol Phys. 2001; 51: 952-8.

24. North CA, Lee DJ, Piantadosi S, Zahurak M, and Johns ME. Carcinoma of the major salivary glands treated by surgery or surgery plus postoperative radiotherapy. Int J Radiat Oncol Biol Phys. 1990; 18: 1319-26.

25. Vander PVL, Balm AJ, Hilgers FJ, Tan IB, Keus RB, and Hart AA. Stage as major long term outcome predictor in minor salivary gland carcinoma. Cancer. 2000; 89: 1195204.

26. Le QT, Birdwell S, Terris DJ, Gabalski EC, Varghese A, We F Jr, and Goffinet DR. Postoperative irradiation of minor salivary gland malignancies of the head and neck. Radiother Oncol. 1999; 52: 165-71.

27. Terhaard CH, Lubsen H, Van der Tweel I, Hilgers FJ, Eijkenboom WM, Marres HA, Tjho-Heslinga RE, de Jong JM, and Roodenburg JL. Salivary gland carcinoma: independent prognostic factors for locoregional control, distant metastases, and overall survival: results of the Dutch head and neck oncology cooperative group. Head Neck. 2004; 26: 681-92; discussion 692-3.

28. Jenkins DW, Spaulding CA, Constable WC, and Cantrell RW. Minor salivary gland tumors: the role of radiotherapy. Am J Otolaryngol. 1989; 10: 250-6.

29. Lupinetti AD, Roberts DB, Williams MD, Kupferman ME, Rosenthal DI, Demonte F, El-Naggar A, Weber RS, and Hanna EY. Sinonasal adenoid cystic carcinoma: the M. D. Anderson Cancer Center experience. Cancer. 2007; 110: 2726-31.

30. Lloyd S, Yu JB, Wilson LD, and Decker RH. Determinants and patterns of survival in adenoid cystic carcinoma of the head and neck, including an analysis of adjuvant radiation therapy. Am J Clin Oncol. 2011; 34: 76-81.

31. Spiro RH, Huvos AG, and Strong EW. Adenoid cystic carcinoma of salivary origin. A clinicopathologic study of 242 cases. Am J Surg. 1974; 128: 512-20.

32. Fordice J, Kershaw C, El-Naggar A, and Goepfert H. Adenoid cystic carcinoma of the head and neck: predictors of morbidity and mortality. Arch Otolaryngol Head Neck Surg. 1999; 125: 149-52.

33. Amit M, Binenbaum Y, Sharma K, Ramer N, Ramer I, Agbetoba A, Glick J, Yang X, Lei D, Bjorndal K, Godballe C, Mucke T, Wolff KD, et al. Incidence of cervical lymph node metastasis and its association with outcomes in patients with adenoid cystic carcinoma. An international 
collaborative study. Head Neck. 2015; 37: 1032-7.

34. Min R, Siyi L, Wenjun Y, Ow A, Lizheng W, Minjun D, and Chenping Z. Salivary gland adenoid cystic carcinoma with cervical lymph node metastasis: a preliminary study of 62 cases. Int J Oral Maxillofac Surg. 2012; 41: 952-7.

35. Vander PV, Bradley PJ, Takes RP, Rinaldo A, Woolgar JA, and Ferlito A. Diagnosis and management of parotid carcinoma with a special focus on recent advances in molecular biology. Head Neck. 2012; 34: 429-40.

36. Vander PV, Hunt J, Bradley PJ, Haigentz M, Rinaldo A, Mendenhall WM, Suarez C, Silver C, Takes RP, and Ferlito A. Recent trends in the management of minor salivary gland carcinoma. Head Neck. 2014; 36: 444-55.

37. Stenner M, Molls C, Luers JC, Beutner D, Klussmann JP, and Huettenbrink KB. Occurrence of lymph node metastasis in early-stage parotid gland cancer. Eur Arch Otorhinolaryngol. 2012; 269: 643-8.

38. Korkmaz H, Yoo GH, Du W, Hocwald E, Otero-Garcia JE, Volkan AN, Shibuya T, and Jacobs JR. Predictors of nodal metastasis in salivary gland cancer. J Surg Oncol. 2002; 80: 186-9.

39. Lloyd S, Yu JB, Ross DA, Wilson LD, and Decker RH. A prognostic index for predicting lymph node metastasis in minor salivary gland cancer. Int J Radiat Oncol Biol Phys. 2010; 76: 169-75.

40. Harbo G, Bundgaard T, Pedersen D, Sogaard H, and Overgaard J. Prognostic indicators for malignant tumours of the parotid gland. Clin Otolaryngol Allied Sci. 2002; 27: 512-6.

41. Jenkins DW, Spaulding CA, Constable WC, and Cantrell RW. Minor salivary gland tumors: the role of radiotherapy. Am J Otolaryngol. 1989; 10: 250-6.

42. Spiro RH, Koss LG, Hajdu SI, and Strong EW. Tumors of minor salivary origin. A clinicopathologic study of 492 cases. Cancer. 1973; 31: 117-29.

43. Armstrong JG, Harrison LB, Thaler HT, Friedlander-Klar H, Fass DE, Zelefsky MJ, Shah JP, Strong EW, and Spiro $\mathrm{RH}$. The indications for elective treatment of the neck in cancer of the major salivary glands. Cancer. 1992; 69: 6159.

44. Lau VH, Aouad R, Farwell DG, Donald PJ, and Chen AM. Patterns of nodal involvement for clinically N0 salivary gland carcinoma: refining the role of elective neck irradiation. Head Neck. 2014; 36: 1435-9.

45. Liu TR, Chen FJ, Zhang GP, and Yang AK. Different therapeutic strategies in primary salivary gland-type nasopharyngeal carcinomas. Curr Opin Otolaryngol Head Neck Surg. 2011; 19: 87-91.

46. Liu S, Ow A, Ruan M, Yang W, Zhang C, Wang L, and Zhang C. Prognostic factors in primary salivary gland mucoepidermoid carcinoma: an analysis of 376 cases in an Eastern Chinese population. Int J Oral Maxillofac Surg. 2014; 43: 667-73.
47. Frankenthaler RA, Byers RM, Luna MA, Callender DL, Wolf P, and Goepfert H. Predicting occult lymph node metastasis in parotid cancer. Arch Otolaryngol Head Neck Surg. 1993; 119: 517-20.

48. Califano L, Zupi A, Massari PS, and Giardino C. Indication for neck dissection in carcinoma of the parotid gland. Our experience on 39 cases. Int Surg. 1993; 78: 347-9.

49. Creagan ET, Woods JE, Schutt AJ, and O'Fallon JR. Cyclophosphamide, adriamycin, and cisdiamminedichloroplatinum (II) in the treatment of advanced nonsquamous cell head and neck cancer. Cancer. 1983; 52: 2007-10.

50. Budd GT, and Groppe CW. Adenoid cystic carcinoma of the salivary gland. Sustained complete response to chemotherapy. Cancer. 1983; 51: 589-90.

51. Venook AP, Tseng A Jr, Meyers FJ, Silverberg I, Boles $\mathrm{R}, \mathrm{Fu} \mathrm{KK}$, and Jacobs CD. Cisplatin, doxorubicin, and 5-fluorouracil chemotherapy for salivary gland malignancies: a pilot study of the Northern California Oncology Group. J Clin Oncol. 1987; 5: 951-5.

52. Dreyfuss AI, Clark JR, Fallon BG, Posner MR, Norris CM Jr, and Miller D. Cyclophosphamide, doxorubicin, and cisplatin combination chemotherapy for advanced carcinomas of salivary gland origin. Cancer. 1987; 60: 2869-72.

53. Creagan ET, Woods JE, Rubin J, and Schaid DJ. Cisplatinbased chemotherapy for neoplasms arising from salivary glands and contiguous structures in the head and neck. Cancer. 1988; 62: 2313-9.

54. Lagha A, Chraiet N, Ayadi M, Krimi S, Allani B, Rifi $\mathrm{H}$, Raies H, and Mezlini A. Systemic therapy in the management of metastatic or advanced salivary gland cancers. Oral Oncol. 2012; 48: 948-57.

55. Andry G, Hamoir M, Locati LD, Licitra L, and Langendijk JA. Management of salivary gland tumors. Expert Rev Anticancer Ther. 2012; 12: 1161-8.

56. Laurie SA, Ho AL, Fury MG, Sherman E, and Pfister DG. Systemic therapy in the management of metastatic or locally recurrent adenoid cystic carcinoma of the salivary glands: a systematic review. Lancet Oncol. 2011; 12: 815-24.

57. Rizk S, Robert A, Vandenhooft A, Airoldi M, Kornek G, and Machiels JP. Activity of chemotherapy in the palliative treatment of salivary gland tumors: review of the literature. Eur Arch Otorhinolaryngol. 2007; 264: 587-94.

58. Tanvetyanon T, Qin D, Padhya T, McCaffrey J, Zhu W, Boulware D, DeConti R, and Trotti A. Outcomes of postoperative concurrent chemoradiotherapy for locally advanced major salivary gland carcinoma. Arch Otolaryngol Head Neck Surg. 2009; 135: 687-92.

59. Maruya S, Namba A, Matsubara A, Kakehata S, Takeda I, Shirasaki T, Hatayama Y, Nagahata M, Yokoyama J, and Shinkawa H. Salivary gland carcinoma treated with concomitant chemoradiation with intraarterial cisplatin and docetaxel. Int J Clin Oncol. 2006; 11: 403-6. 
60. Pederson AW, Salama JK, Haraf DJ, Witt ME, Stenson KM, Portugal L, Seiwert T, Villaflor VM, Cohen EE, Vokes EE, and Blair EA. Adjuvant chemoradiotherapy for locoregionally advanced and high-risk salivary gland malignancies. Head Neck Oncol. 2011; 3: 31.

61. Schoenfeld JD, Sher DJ, Norris CM, Haddad RI, Posner MR, Balboni TA, and Tishler RB. Salivary gland tumors treated with adjuvant intensity-modulated radiotherapy with or without concurrent chemotherapy. Int J Radiat Oncol Biol Phys. 2012; 82: 308-14.

62. Hsieh CE, Lin CY, Lee LY, Yang LY, Wang CC, Wang HM, Chang JT, Fan KH, Liao CT, Yen TC, Fang KH, and Tsang YM. Adding concurrent chemotherapy to postoperative radiotherapy improves locoregional control but not overall survival in patients with salivary gland adenoid cystic carcinoma-a propensity score matched study. Radiat Oncol. 2016; 11: 47.

63. Tanvetyanon T, Fisher K, Caudell J, Otto K, Padhya T, and Trotti A. Adjuvant chemoradiotherapy versus with radiotherapy alone for locally advanced salivary gland carcinoma among older patients. Head Neck. 2016; 38: 86370.

64. Amini A, Waxweiler TV, Brower JV, Jones BL, McDermott JD, Raben D, Ghosh D, Bowles DW, and Karam SD. Association of Adjuvant Chemoradiotherapy $v s$ Radiotherapy Alone With Survival in Patients With Resected Major Salivary Gland Carcinoma: Data From the National Cancer Data Base. JAMA Otolaryngol Head Neck Surg. 2016, doi:10.1001/jamaoto.2016.2168.

65. Mifsud MJ, Tanvetyanon T, Mccaffrey JC, Otto KJ, Padhya TA, Kish J, Trotti AM, Harrison LB, and Caudell JJ. Adjuvant radiotherapy versus concurrent chemoradiotherapy for the management of high-risk salivary gland carcinomas. Head Neck. 2016, doi 10.1002/ hed.24484.

66. Mino M, Pilch BZ, and Faquin WC. Expression of KIT (CD117) in neoplasms of the head and neck: an ancillary marker for adenoid cystic carcinoma. Mod Pathol. 2003; 16: 1224-31.

67. Dodd RL, and Slevin NJ. Salivary gland adenoid cystic carcinoma: a review of chemotherapy and molecular therapies. Oral Oncol. 2006; 42: 759-69.

68. Holst VA, Marshall CE, Moskaluk CA, and Frierson HF Jr. KIT protein expression and analysis of c-kit gene mutation in adenoid cystic carcinoma. Mod Pathol. 1999; 12: 956-60.

69. Jeng YM, Lin CY, and Hsu HC. Expression of the c-kit protein is associated with certain subtypes of salivary gland carcinoma. Cancer Lett. 2000; 154: 107-11.

70. Penner CR, Folpe AL, and Budnick SD. C-kit expression distinguishes salivary gland adenoid cystic carcinoma from polymorphous low-grade adenocarcinoma. Mod Pathol. 2002; 15: 687-91.

71. Guigay JM, Bidault F, Temam S, Janot F, Raymond E and
Faivre S. Antitumor activity of imatinib in progressive, highly expressing KIT adenoid cystic carcinoma of the salivary glands: a phase II study. Proc Am Soc Clin Oncol. 2007; 25: abstract 6086 .

72. Slevin NJ, Mais KL, Bruce I. Imatinib with cisplatin in recurrent and/ormetastatic adenoidcystic carcinomapreliminary results of a phase II study of 18 patients with response assessed by morphological and functional imaging. Eur J Cancer Suppl. 2005; 3: 292-3.

73. Ochel HJ, Gademann G, Rocken C, and Wordehoff H. Effects of imatinib mesylate on adenoid cystic carcinomas. Anticancer Res. 2005; 25: 3659-64.

74. Lin CH, Yen RF, Jeng YM, Tzen CY, Hsu C, and Hong RL. Unexpected rapid progression of metastatic adenoid cystic carcinoma during treatment with imatinib mesylate. Head Neck. 2005; 27: 1022-7.

75. Hotte SJ, Winquist EW, Lamont E, MacKenzie M, Vokes E, Chen EX, Brown S, Pond GR, Murgo A, and Siu LL. Imatinib mesylate in patients with adenoid cystic cancers of the salivary glands expressing c-kit: a Princess Margaret Hospital phase II consortium study. J Clin Oncol. 2005; 23: 585-90.

76. Pfeffer MR, Talmi Y, Catane R, Symon Z, Yosepovitch A, and Levitt M. A phase II study of Imatinib for advanced adenoid cystic carcinoma of head and neck salivary glands. Oral Oncol. 2007; 43: 33-6.

77. Alcedo JC, Fabrega JM, Arosemena JR, and Urrutia A. Imatinib mesylate as treatment for adenoid cystic carcinoma of the salivary glands: report of two successfully treated cases. Head Neck. 2004; 26: 829-31.

78. Faivre S, Raymond E, Casiraghi O, Temam S, and Berthaud P. Imatinib mesylate can induce objective response in progressing, highly expressing KIT adenoid cystic carcinoma of the salivary glands. J Clin Oncol. 2005; 23: 6271-3; author reply 6273-4.

79. Hitre E, Budai B, Takacsi-Nagy Z, Rubovszky G, Toth E, Remenar E, Polgar C, and Lang I. Cetuximab and platinum-based chemoradio- or chemotherapy of patients with epidermal growth factor receptor expressing adenoid cystic carcinoma: a phase II trial. Br J Cancer. 2013; 109: 1117-22.

80. Krikelis D, Bobos M, Karayannopoulou G, Resiga L, Chrysafi S, Samantas E, Andreopoulos D, Vassiliou V, Ciuleanu E, and Fountzilas G. Expression profiling of 21 biomolecules in locally advanced nasopharyngeal carcinomas of Caucasian patients. BMC Clin Pathol. 2013; 13: 1 .

81. Agulnik M, Cohen EW, Cohen RB, Chen EX, Vokes EE, Hotte SJ, Winquist E, Laurie S, Hayes DN, Dancey JE, Brown S, Pond GR, Lorimer I, et al. Phase II study of lapatinib in recurrent or metastatic epidermal growth factor receptor and/or erbB2 expressing adenoid cystic carcinoma and non adenoid cystic carcinoma malignant tumors of the salivary glands. J Clin Oncol. 2007; 25: 3978-84. 
82. Argiris A, Ghebremichael M, Burtness B, Axelrod RS, Deconti RC, and Forastiere AA. A phase 2 trial of bortezomib followed by the addition of doxorubicin at progression in patients with recurrent or metastatic adenoid cystic carcinoma of the head and neck: a trial of the Eastern Cooperative Oncology Group (E1303). Cancer. 2011; 117: 3374-82.

82. Dimery IW, Jones LA, Verjan RP, Raymond AK, Goepfert $\mathrm{H}$, and Hong WK. Estrogen receptors in normal salivary gland and salivary gland carcinoma. Arch Otolaryngol Head Neck Surg. 1987; 113: 1082-5.

84. Shick PC, Riordan GP, and Foss RD. Estrogen and progesterone receptors in salivary gland adenoid cystic carcinoma. Oral Surg Oral Med Oral Pathol Oral Radiol Endod. 1995; 80: 440-4.
85. Jeannon JP, Soames JV, Bell H, and Wilson JA. Immunohistochemical detection of oestrogen and progesterone receptors in salivary tumours. Clin Otolaryngol Allied Sci. 1999; 24: 52-4.

86. Ozono S, Onozuka $\mathrm{M}$, Sato $\mathrm{K}$, and Ito $\mathrm{Y}$. Immunohistochemical localization of estradiol, progesterone, and progesterone receptor in human salivary glands and salivary adenoid cystic carcinomas. Cell Struct Funct. 1992; 17: 169-75.

87. Fan CY, Melhem MF, Hosal AS, Grandis JR, and Barnes EL. Expression of androgen receptor, epidermal growth factor receptor, and transforming growth factor alpha in salivary duct carcinoma. Arch Otolaryngol Head Neck Surg. 2001; 127: 1075-9. 